\title{
La investigación urbana en México, 1980-1990*
}

\section{Araceli Damián**}

El objetivo del presente trabajo es hacer un balance de la investigación urbana en México durante la década de los ochenta. El análisis ofrecido es un mosaico desigual, que refleja el estado del conocimiento de las diversas disciplinas que pretenden abarcar lo urbano, así como los principales tópicos desarrollados. El estudio se divide en tres apartados: 1) temas que persisten; 2) nuevos temas de lo urbano y 3) las políticas del Estado en torno a lo urbano. Se describe cómo en los ochenta se realizan investigaciones que tienen como objetivo hacer un análisis más explícito de la realidad urbana, retomando los temas abordados durante los setenta, pero abandonando las grandes generalizaciones e incorporando temas poco estudiados con anterioridad, tales como el transporte, los servicios, el im. pacto ambiental del desarrollo económico, los problemas de alimentación y salud. En lo que se refiere a políticas estatales se describen los estudios que tratan de vincular la política estatal, los actores involucrados y su im. pacto (o no) en los procesos de urbanización, así como la normatividad de la intervención estatal.

No sólo se trataron los viejos temas como el de la vivienda, el de Ia urbanización y el de los movimientos sociales, sino que se enriquecieron con la crítica iniciada a partir de los planteamientos de los setenta. En esta década proliferan las investigaciones de corte empírico y son realizadas de manera individual o en pequeños grupos, limitando el alcance y profundidad en los temas; sin embargo, se ha logrado comprender situaciones particulares de la realidad urbana.

La evolución de los tópicos de investigación se encuentran en gran medida determinados por los procesos sociales, por el desarrollo de la ciencia y en algunos casos por las condiciones del medio académico y de los investigadores en sí mismos. Al no existir una teoría general de lo urbano, el rigor metodológico de su investigación depende sobre todo de los avatares de las disciplinas sociales.

El impacto en las estructuras socioeconómicas de diversos

* Este trabajo constituye parte de los avances del proyecto titulado "Medio siglo de investigación urbano-regional en México, 1940-1990", realizado conjuntamente con el Dr. Gustavo Garza, en el Centro de Estudios Demográficos y de Desarrollo Urbano de El Colegio de México.

** Investigadora del Centro de Estudios Demográficos y de Desarrollo Urbano de El Colegio de México. 
acontecimientos influyeron, de alguna manera, en la dinámica y las preocupaciones del sector académico. La crisis en México, que irrumpe en 1982, tuvo como principales características: la imposibilidad de hacer frente a una creciente deuda externa, la elevación de la tasa inflacionaria y de las tasas de interés, la caída en los precios del petróleo, la fuga de capitales, los élevados déficit en la balanza comercial; las abruptas devaluaciones, el desempleo, etcétera. Lo anterior tuvo como algunas de sus principales consecuencias el deterioro de las condiciones de vida de la población, la fragmentación del control del sistema político y la proliferación del sector informal y la pobreza urbana.

A pesar de la crisis, se han seguido creando algunos centros de investigación y docencia después de 1980, estimándose que la mitad de los existentes son posteriores a esa fecha, no obstante, su proceso de consolidación se ha visto frenado por el decaimiento de los salarios reales en el sector académico y por la reducción del monto de recursos estatales y privados para el fomento de esta actividad.

A raiz de los sismos de 1985 en la ciudad de México se dieron nuevas formas de convivencia social y se promovió una vinculación más estrecha entre el sector académico y los sectores populares. Con ello aumentó el interés por aspectos de la vida cotidiana, estrategias de sobrevivencia, movimientos sociales y la democratización en el país. Por último, otro acontecimiento social, que consideramos pudo haber influido en las prioridades de investigación, fue el de la elección presidencial de 1988, que hizo evidente el deterioro del control político ejercido por el partido oficial.

Creemos que los factores antes mencionados son, entre muchos otros, lo que conformaron el contexto al que se enfrentó la práctica de investigación.

El objetivo del presente artículo es hacer una revisión y descripción temática de algunos trabajos relevantes que han contribuido al desarrollo de la investigación urbana en México durante la década de los ochenta, no pretendiendo agotar todo el material producido y dejando como tarea pendiente la profundización en los avances teóricos metodológicos logrados hasta el momento. ${ }^{1}$

\footnotetext{
${ }^{1}$ Como se mencionó anteriormente, este trabajo se inscribe en una investigación que tiene alcances mayores a los que aquí se presentan. Considerando el periodo de estudio se tienen registradas $X$ fichas bibliográficas que hacen referencia a temas urbano-regionales, lo que representa un trabajo exhaustivo en la búsqueda. Sin embargo, ante la imposibilidad de presentar un material tan vasto se eligieron algunos textos que consideramos son relevantes en cuanto a las temáticas abordadas. Hablaremos en este trabajo de algunas investigaciones que de cierta manera delimitan los procesos socioespaciales en forma regional o nacional, pero que se
} 


\section{Temas que persisten}

Las modificaciones en la estructura productiva de México a partir de 1940 y el rápido crecimiento de su población tuvieron un impacto directo en los procesos de urbanización. La gran concentración económica y de población fueron los temas tratados inicialmente por la investigación urbano-regional en nuestro país. La mayor parte de los estudios que se realizaron desde los años cuarenta hasta los sesenta se inscriben fundamentalmente dentro de dos corrientes. La primera, que nace de los planteamientos de la escuela neoclásica, estudia la ordenación de los asentamientos por tamaño de población, a través de modelos como el de primacía y el de rango-tamaño, o bien de los gravitacionales, que miden la interacción funcional entre localidades. Como ejemplo de este tipo de enfoque tenemos los realizados por Unikel, los cuales tienen un elevado nivel técnico metodológico. La otra vertiente fue la ecología humana, que establece un conjunto de paradigmas sobre la ciudad como área natural, el modelo de círculos concéntricos y el proceso ecológico que determina la estructura de la comunidad. Posteriormente estos enfoques fueron abandonados casi por completo al incorporarse la orientación funcionalista de las teorías de la modernización y la marginalidad, que intentan explicar la existencia de grandes masas de trabajadores urbanos no integrados a la sociedad urbana. En los setenta y sobre todo a principios de los ochenta, las distintas vertientes del materialismo histórico cobran fuerza, destacando aquellas que se basan en la sociología urbana francesa. Los trabajos estudian el problema urbano en el contexto de la acumulación de capital y las contradicciones entre clases sociales, inscribiendo a la ciudad como marco de reproducción de la fuerza de trabajo. De esta manera son importantes aquellos trabajos que se refieren al Estado, a los movimientos sociales, al problema de la vivienda, etc. Creemos que esta corriente de pensamiento es la que ha tenido un mayor desarrollo

abocan fundamentalmente a hacer énfasis en la estructuración inter e intra urbana. A] interior de lo que denominamos lo "urbano", intentaremos hacer una distinción temática, reconociendo que a] interior pueden estar tratadas con instrumentales de disciplinas diversas (economía, sociologí, historia, etc.), o bien, de manera interdisciplinaria. Asimismo, incorporamos trabajos referentes a estudios no necesariamente abordados desde la óptica de lo urbano, que sin embargo, ayudan a la comprensión de dicho fenómeno; ejemplo de ello es el tema del mercado de trabajo en las ciudades que ha sido estudiado por la sociología laboral. Hemos seleccionado algunas monografías por considerarlas importantes esfuerzos de sistematización de la información que se constituyen en referencia obligada para algunos temas de investigación. 
teórico en torno al fenómeno urbano. El cambio operado dentro de la investigación no respondió, mecánicamente, a las bruscas modificaciones del contexto social y económico; más bien nos encontramos con el tratamiento más explícito de temáticas abordadas desde los setenta, así como de la problematización de ciertos aspectos poco estudiados anteriormente. Así tenemos, sólo por senalar un ejemplo, que dentro del estudio de los procesos habitacionales, se incorpora la problemática de la vivienda en alquiler.

\section{Estructura urbana y distribución espacial de la población}

No obstante que ha sido abandonado el análisis de la escuela de Chicago, se continúan utilizando algunos de sus modelos como herramienta práctica para estudiar y describir fenómenos urbanos. De esta manera encontramos el trabajo de Negrete y Salazar (1986), quienes utilizan los anillos concéntricos para la descripción de la expansión de la ciudad de México, sus cambios de densidades del centro a la periferia, la incorporación de nuevas unidades administrativas y los cambios en la distribución de la población y en los usos del suelo. Schteingart y Rubalcava (1985) a través del análisis factorial de datos censales (equipamiento, servicios básicos, ingresos, escolaridad, etc.), muestran las diferencias socioespaciales intraurbanas en la ciudad de México, donde se observan anillos concéntricos cuando se trata de grados de consolidación urbana, y en lo que se refiere a las diferencias internas en la ciudad se tiene un esquema no concéntrico. Terrazas (1988), nos presenta la estructura funcional de la ZMCM, Delgado (1990), basándose en los conceptos de ciudad interior y anillos concéntricos, analiza las formas que han caracterizado el crecimiento de la ciudad de México en sus diferentes etapas, resaltando los procesos de consolidación-segregación y crecimiento masivo-expansivo de la ciudad, basándose en el estudio de la distribución de servicios y equipamiento. Sobre los flujos intraurbanos y la jerarquía de centros en Monterrey, se centra la investigación de Quintanilla (1986).

Pocos trabajos se han realizado desde la perspectiva de la geografía urbana; uno de ellos fue el Atlas de la Ciudad de México, editado en 1987, que describe las características físico-geográficas de la cuenca de México. Esta obra rebasa los objetivos de una investigación geográfica al incluir aspectos históricos, demográfícos, económicos, urbanísticos y políticos. Se realizó una restructuración y actualización general del trabajo, extendiendo el análisis a toda la Zona Metropolitana de la Ciudad de México (G. Garza et al., 1987). 
Sobre la distribución de la población y el sistema de ciudades en el pais, tenemos los trabajos de Negrete y Salazar (1986), Brambila y Salazar [1984], González de Alba [1984) y Ruiz (1990). Asimismo está el de H. Salazar (1984) sobre la dinámica de crecimiento de las ciudades intermedias demostrando que éstas tienen ritmos de crecimiento superiores a los de la ciudad de México. También Merla $[1983,1986)$ describe el crecimiento explosivo de Monterrey y su área metropolitana. En la mayorfa de éstos se usan los modelos de primacía y rango-tamaño para la explicación de la dinámica de las ciudades en México, utilizando variables demográficas y funcionales.

En esta misma línea encontramos el trabajo de I. Scott (1982) quien hace un estudio en un nivel nacional sobre la relación entre estructura urbana y desarrollo económico, identificando regiones y ciudades por tamaño; describe las implicaciones demográficas y económicas de la fuerte concentración en la ciudad de México para el desarrollo urbano del país.

En las publicaciones sobre migración, desaparecen aquellos trabajos que ponen de manifiesto los fuertes flujos hacia la ciudad de México, dando paso a los que se refieren a otras ciudades. En este caso se encuentran el de Quintanilla (1989) y el de Zúñiga (1988), que analizan las migraciones hacia Monterrey. Sobre Guadalajara, están los estudios de Arroyo y De la Peña (1990), y Velázquez (1989).

Aun cuando, en la mayorfa de las investigaciones antes señaladas, la delimitación de lo urbano se realiza con criterios ecológico-demográficos que suelen sujetar la realidad a modelos a priori, abren la posibilidad por un lado, a través de indicadores empíricos, de observar la organización territorial de la ZMCM y por otro, de explorar las interrelaciones que se establecen entre el arreglo espacial de la población y los procesos socioeconómicos.

\section{Urbanización y procesos económicos}

Considerando el papel crucial de la industria en el desarrollo económico del país y sus importantes vinculaciones territoriales, sorprende constatar que los trabajos sobre industria son escasos. Éstos se centran en estudiar los patrones de localización industrial y sus implicaciones para el modelo de desarrollo, la dinámica y estructura del sector y el crecimiento industrial de las principales ciudades del país; sobre todo, la concentración de la industria en la ciudad de México en las distintas etapas de desarrollo (Garza $1980,1983,1985,1988$ a y 1988b). 
La relación entre el crecimiento de la industria manufacturera y el desarrollo urbano en la frontera México-Estados Unidos está planteada en el trabajo de Suárez Villa (1985). Asimismo, Treviño [1988) analiza el emplazamiento industrial en Monterrey y su impacto en el proceso de urbanización. En lo que se refiere a la industria en Guadalajara está el libro de Alba y Kruijt (1988), el de De la Peña y Escobar (comps.) (1986), y los de Arias (1985), Escobar y Rocha (1988) y Giner (1990); los dos primeros autores abordan temas sobre los problemas urbano-regionales y la conformación de clases sociales en torno a esta actividad y, los otros, del proceso de industrialización en Guadalajara caracterizado por la proliferación de la pequeña y mediana industrias.

Sobre el tema de servicios se realizó el trabajo de Levi, et al. (1981), en él, los autores hacen una descripción de este sector en el área central de la ciudad de México. El texto de Rello y Sodi (1989) es de mayor profundidad, ya que analiza la problemática de la distribución de alimentos en la ciudad de México. En este mismo tema se inscriben las investigaciones de Castillo (1987) y de Tello (1988). El interés de los trabajos antes mencionados está vinculado básicamente a los efectos que tiene la actividad económica en la estructuración y organización territorial; no obstante, surgieron otra serie de estudios que no tienen un referente explícito con este fenómeno, sino que dan cuenta de las repercusiones del desarrollo económico en las condiciones laborales de los trabajadores urbanos. Con un enfoque más sociológico, nos encontramos con el análisis sobre la participación en el mercado de trabajo y la composición familiar en los hogares de trabajadores de la ciudad de México (García et al, 1982); asimismo localizamos trabajos que hablan sobre Guadalajara (Roberts, 1986; De la Peña, 1986 y 1990).

La crisis económica provocó un mayor desempleo y subempleo que han hecho que, sobre todo en las principales ciudades del país, aumente la cantidad de población que depende de la actividad informal. Los fundamentos teóricos utilizados para el análisis de la dinámica de este sector, son expuestos por Connolly (1990); Víctor Tokman (1983) realiza un estudio comparativo entre diversos países latinoamericanos tomando como ejemplo a México, para determinar la influencia que tiene el sector informal urbano en la distribución del ingreso. En lo que se refiere al impacto de la crisis económica en el mercado de trabajo de la ZMCM y la incorporación al mercado formal o informal, está el texto de Jusidman (1988). Para Guadalajara, el trabajo de Escobar (1986), hace énfasis en los procesos industriales, y los de González de la Rocha [1986) giran en torno a las estrategias de sobrevivencia familiar. 
El rápido crecimiento poblacional que han tenido las ciudades y la capacidad de absorción de los mercados formales de trabajo fronterizos ha propiciado el aumento de actividades informales, sobre todo en Tijuana y Ciudad Juárez (Méndez, 1990).

Una perspectiva económica global, que utiliza los planteamientos del materialismo histórico, es aquella que estudió la relación entre procesos de urbanización y restructuración del capitalismo durante la década, considerando la concentración urbana e industrial, las nuevas áreas de producción y el cambio en la participación estatal (Pradilla, 1990 y Pradilla y Castro, 1989).

Temas clásicos de la sociología urbana

Los estudios sociológicos en México fueron influidos por autores como Lojkine, Topalov y Castells, los cuales construyeron una teoría de lo urbano con base en la acumulación del capital, la lucha de clases y una concepción clasista del Estado. La cuestión urbana fue categorizada por temàs como la intervención creciente del Estado en el consumo colectivo; los movimientos sociales urbanos; las condiciones de vida de los trabajadores, con especial énfasis en la vivienda; el papel del capital inmobiliario y financiero en la conformación de la estructura urbana, etc. A continuación se presentan algunos trabajos que se inscribieron en esta línea durante la década de los ochenta.

\section{Movimientos sociales urbanos}

La investigación de los movimientos sociales urbanos recibe un tratamiento más explícito que en las décadas anteriores. Este tema puede considerarse como uno de los más socorridos dentro de la sociología urbana en el periodo, seguramente por el constante decaimiento de las condiciones de vida y la subsecuente respuesta de los grupos populares. Se busca comprender las acciones de los sectores populares a partir de sus problemas y necesidades, enfatizando el conflicto entre clases y la participación del Estado para garantizar la reproducción de la fuerza de trabajo. En la mayoría de los trabajos, la intervención del Estado queda como una condición estructural ante la insuficiencia del salario para satisfacer ciertas necesidades, tales como la vivienda, la educación, la salud, entre otras. Estos estudios se refieren a los movimientos sociales como resultado de las condiciones de reproducción de la fuerza de trabajo y tratan, fundamentalmente, de las formas de 
apropiación del suelo y de vivienda; se extienden, posteriormente, al estudio de las demandas de servicios como el transporte, el abasto, etc. (Moctezuma y Navarro, 1984 y 1989; Jorge Alonso, 1980 y Jorge Alonso, comp., 1986; Moctezuma, 1981, 1984 y 1986; Núñez, 1982a y 1990 y Ramírez 1984, 1986, Ramírez, coord., 1987).

Moctezuma y Navarro analizan la relación que se establece entre la organización social para la ocupación del territorio y el sistema público de reproducción social. Moctezuma estudia la Coordinadora Nacional del Movimiento Urbano (Conamup), sobre todo en lo que se refiere al Valle de México, como una de las principales formas de organización popular no subordinadas al partido oficial, Jorge Alonso, comp. (1986) reúne una serie de investigaciones sobre los distintos movimientos sociales, tanto de las organizaciones urbanas populares, como de otras capas sociales, destacando los temas de los movimientos en torno al transporte, el abasto, los trabajadores independientes, las mujeres, los jóvenes (bandas), estudiantes y comunidades cristianas.

Schteingart (1987) incorpora el aspecto de la preservación del medio ambiente en torno a la lucha popular por el espacio urbano. Se han realizado trabajos en torno al movimiento inquilinario (Bassols, 1989) y sobre bandas juveniles (Aliemann), no obstante, los trabajos no han rebasado la crónica y la descripción. Sobre el movimiento social en otras ciudades tenemos los que se refieren a Guadalajara (Regalado, 1986; Safa, 1987 y Romero, 1990) y a Puebla (Jaime Castillo, coord., 1986).

El problema del movimiento urbano popular durante la crisis se encuentra ampliamente documentado por Ángel Mercado (1989), quien hace una compilación de sus ensayos periodísticos. Más recientemente, encontramos estudios que analizan la relación de] movimiento urbano popular con la sociedad civil y con el gobierno del Distrito Federal, así como el proyecto de ciudad para cada uno de estos sectores (J.M. Ramírez, coord., 1987). Cabe destacar la aparición del trabajo de Aguilar (1988) donde por primera vez se relacionan los planteamientos de la psicología social y el movimiento urbano popular.

El tema de las organizaciones sociales urbanas no puede apartarse de la caracterización de lo político en la ciudad, considerando el papel del Estado como uno de los principales agentes de la conformación urbana y la problemática de la expansión urbana sobre terrenos ejidales. Este tema se entrelaza también con los procesos de uso y apropiación del área central de la ciudad de México, con el del capital inmobiliario y finalmente, con las nuevas modalidades del movimiento urbano popular a raíz de los sismos de 1985 (Coulomb y Duhau, coords., 1988; Iracheta y Villar, comps., 1988). 
Este tipo de estudios son fundamentalmente descriptivos; hablan sobre las formas concretas de organización social, las diversas coyunturas y sus aciertos y fracasos, sin lograr caracterizar el impacto del movimiento social en la estructuración y transformación del territorio. Una vertiente distinta a los enfoques tradicionales fue la que analizó las transformaciones culturales de ciertos sectores populares. Algunos se refieren, por un lado, a las transformaciones de las costumbres y comportamientos de grupos indígenas inmigrantes a la ciudad de México (Lira, 1983 y Barba, 1985) y, por otro, a cómo la expansión metropolitana en el Valle de México absorbe poblaciones de origen rural y con ello se modifican las necesidades, los patrones culturales y las formas de organización de los pobladores (Arau, 1987). Por último, tenemos el trabajo de Reyes y Rosas (1985) sobre los aspectos culturales y la organización popular en el singular caso de Tepito y, el de Núñez (1984 y 1990), en donde se analizan los nuevos patrones culturales en los movimientos urbanos independientes.

\section{La problemática habitacional y la urbanización popular}

Otro de los grandes temas en los estudios urbanos es el de la vivienda y los asentamientos irregulares. Una de las principales características de las investigaciones en el caso de la vivienda es que se abandonan los diagnósticos que testimonian la imposibilidad de atender la demanda por los sectores formales de producción habitacional y, en cuanto a los asentamientos populares, se desplaza el concepto de marginalidad urbana, provocando que en los años ochenta se avance hacia análisis más comprensivos de las características urbanas. Así, las nuevas investigaciones intentan diagnosticar las condiciones de vida de la población urbana popular, incorporando la acción de los distintos sujetos involucrados en los procesos de urbanización popular, en un intento por trascender la comprensión del problema de la vivienda en términos de producción y déficit. En cuanto a las principales formas de producción y circulación de vivienda se distingue a la promoción inmobiliaria privada y estatal, a la autoconstrucción y a la construcción por encargo.

En algunos casos el análisis se centra en las políticas habitacionales y en la evaluación de los programas estatales de vivienda [Schteingart, 1982 y 1989; Mier y Terán y Ziccardi, 1985]. Otros autores investigan más concretamente sobre las instituciones y mecanismos gubernamentales encargadas de la vivienda como Infonavit, Fonhapo, Fovi, etc. [Robinson, 1980; Román, 1983; García 
y Perló, 1984; Núñez, 1982b; Duhau, 1988b.) Estos estudios analizan la intervención estatal en términos de su participación en la urbanización del suelo y en sus formas de vinculación con la producción y circulación de vivienda.

La dinámica de la producción inmobiliaria en la zona metropolitana de la ciudad de México es analizada por Schteingart [1983b, 1988, 1989) y por Ball y Conolly (1987); para el caso de Guadalajara y Querétaro por García Peralta $[1986,1989)$ y para las ciudades petroleras por Legorreta (1983). Se puede decir que a través de las categorías de análisis de la sociología francesa, se logró un estudio exhaustivo de las formas de producción del territorio urbano, incorporando sus diferentes actores y modalidades. Uno de los principales logros de estos trabajos fue la constatación de que la lógica del capital inmobiliario no explica en sí misma la organización del espacio urbano (como se planteó teóricamente en los setenta), dándole a iravés del análisis empírico su dimensión real dentro de este proceso.

En cuanto a la vivienda de alquiler están los trabajos de Portillo (1984) y Coulomb [1985 y 1988); en ellos se analiza el tema de la vivienda en renta en la ciudad de México. El primero, apoyado en el instrumental de la sociología urbana francesa, estudia la dinámica de este tipo de vivienda con relación en la teoría de la renta y su vinculación con la problemática habitaciona] popular. El segundo autor, habla de la proliferación de la vivienda en renta en las zonas periféricas como un indicador de su consolidación.

La autoconstrucción y consolidación de la vivienda popular cobra mayor importancia a raiz de la crisis económica de la década. Para la ciudad de México tenemos el trabajo de Conolly (1980), Jan Bazant [1985] y Pradilla [1982 y 1988); para las ciudades de Guadalajara, Tijuana, Monterrey y las ciudades petroleras, están los del centro de Ecodesarrollo (Legorreta, 1984; Hiernaux, 1986; Castañeda y Villarreal, 1986 y López Rangel, 1987). En este conjunto de trabajos se abordan los procesos de urbanización a través del estudio de las formas ilegales de apropiación del suelo, los procesos de regularización y estructuración de los asentamientos populares, la lucha de los pobladores frente al Estado y los programas oficiales de autoconstrucción. En los trabajos desarrollados en el Centro de Ecodesarrollo, así como en los de Connolly (1988a y 1988 b) se evidencia que aquellas categorías utilizadas en la comprensión de la dinámica del sector inmobiliario (lenta rotación de capital e irreproductibilidad del suelo), eran insuficientes, abordando de esta manera el estudio de la estructura técnica-productiva y las formas de explotación de la fuerza de trabajo.

En lo que se refiere a la expansión metropolitana popular. 
apropiación del espacio urbano, renta del suelo, tenencia de la tierra y política urbana se agregan las investigaciones de Schteingart (1981b), Mier y Terán (1982), Cisneros (1981), Bejarano (1983), Durand (1983), Iracheta, coord. (1984, 1988a y 1988b), Varley (1985), Calderón [1987) y Azuela (1989c). Estos trabajos plantean que los asentamientos irregulares fueron una forma en la que el Estado dio salida a la demanda popular de suelo urbano, intentando establecer la relación entre organización social y la política estatal encaminada a la reproducción de las masas populares. Iracheta presenta el problema del suelo urbano de los municipios conurbados del Estado de México, analizando los diversos agentes (capital inmobiliario y bancario, Estado y sector popular).

En esta misma línea es necesario mencionar los estudios de A. Azuela (1982, 1984, 1988a y 1989a), en los que se aborda el tema poco explorado de los aspectos jurídicos y políticos de los asentamientos irregulares, enfatizando sobre las implicaciones legales que tiene la expansión urbana sobre terrenos con propiedad social y estatal (ejidales y comunales). En estos trabajos se analizan las relaciones sociales de propiedad, en la cual se involucran diversos actores para conformar un mercado "ilega]" de] suelo.

\section{Historia urbana}

Esta línea de investigación fue seguida por Alejandra Moreno Toscano en los setenta, sobre todo en lo referente a la ciudad de México. Sin embargo, este tipo de estudios desaparecen casi por completo a principios de los ochenta, y resurgen en la segunda mitad de la década. Duhau (1982 y 1987b) investiga la actividad económica de la ciudad de México durante el periodo colonial; Hira de Gortari (1982) nos habla de la economía de la ciudad de México durante el periodo que antecedió a la Revolución y, sobre este mismo periodo, en lo que se refiere a la problemática urbana nos encontramos con los trabajos de Yamada [1983a, 1983b). Cerutti se ha dedicado a estudiar la conformación histórica de Monterrey, abarcando aspectos que están relacionados con la conformación histórica regional, en el periodo que abarca desde la independencia hasta la época cardenista; asimismo, toca temas relacionados con la problemática actual de la ciudad (ingreso, actividad económica, servicios, crecimiento demográfico y migraciones) (Cerutti, coord., 1987, 1988). Otros trabajos de este autor nos muestran la conformación capitalista de Monterrey, sobre todo a finales del siglo pasado y los albores de] presente [Cerutti, 1982, 1983). 
Sobre la ciudad de México, Hira de Gortari y Regina Hernández [1988a, 1988b) presentan dos libros. El primero es una recopilación de documentos y fuentes relativas al Distrito Federal, desde su creación como entidad política en 1824, hasta la abolición de sus municipios en 1928. El segundo se refiere al periodo en e] que se pensaba trasladar la capital hacia Querétaro, hasta la creación del Departamento del Distrito Federal, introduciendo un análisis de los cambios en la estructura urbana durante esa época. Jonathan Kandell (1990) realiza una crónica sobre la transformación de la ciudad desde el imperio azteca hasta los sismos de 1985.

Existen numerosos trabajos de carácter histórico sobre la ciudad de México (fundación, etapa colonial, arquitectura, política, etc.), sin embargo, falta retomarlos y complementarlos con el instrumental metodológico desarrollado por la moderna ciencia urbano-regional.

\section{Nuevos temas sobre lo urbano}

La complejidad del fenómeno urbano ha llevado a la sociología a estudiar nuevos objetos y ienómenos, particularizando los estudios en aspectos tales como el transporte, los servicios, los desastres naturales, el impacto ambiental del desarrollo económico, los problemas de alimentación y salud, en fin, una serie de procesos que requieren de un análisis más específico y que no surgen necesariamente del paradigma de la urbanización capitalista que dominó a la década de los setenta y la primera mitad de los ochenta; es en esta última cuando proliferan las investigaciones en torno a tales tópicos; sin embargo, como son realizadas de manera individual o en pequeños grupos, el alcance y profundidad en los temas es limitado. Aun así, ello ha permitido superar las grandes generalizaciones del fenómeno urbano, adentrándose en situaciones particulares de la realidad.

\section{Infraestructura y servicios urbanos}

El papel jugado por los llamados medios de consumo colectivo o condiciones generales para la producción fue un tema bastante discutido a nivel teórico durante los setenta, no obstante, no se realizaron esfuerzos por constatar empíricamente este fenómeno. En los ochenta se inician algunas líneas de investigación en torno a la infraestructura y servicios urbanos, mas su proliferación fue considerablemente menor que en otros tópicos. Uno de los ele- 
mentos infraestructurales más estudiados fue el del transporte, ante la rápida expansión de la mancha urbana de la ciudad de México, que en la actualidad se estima en alrededor de 1400 kilómetros cuadrados, y que implica largos desplazamientos de la población, entre Jos Jugares de vivienda y trabajo. Las características de este fenómeno son analizadas por autores como Gutiérrez MacGregor et al. (1983), Ibarra (1981, 1983); Navarro (1984 y 1988), y Navarro y González [1989). Ibarra se centra en un análisis conceptual de las funciones del transporte público, las necesidades de traslado de la mano de obra y la participación del Estado. Navarro realiza un análisis del papel del Sistema de Transporte Colectivo Metro en la movilización de la fuerza de trabajo metropolitana. Sobre la problemática del transporte de los municipios conurbados del Estado de México se encuentra la investigación de A. Iracheta, coord. (1983). Legorreta y Flores (1989) plantean la problemática del transporte con relación a la contaminación, estableciendo la relación entre las formas de organización y gestión del mismo con la estructuración de la Zona Metropolitana de la Ciudad de México. Camarena [1987) nos presenta algunos de los problemas urbanos y regionales que se han generado por la enorme concentración del transporte de carga en la ciudad de México.

Pocos estudios se han realizado en torno a otros servicios como educación, salud, abasto, etc. No obstante encontramos trabajos sobre educación para el caso de Monterrey como el de Stinson (1983) y el de Zúniga (1987) y, en cuanto al agua, está el de Bennett (1988) y el de Duarte (1988). De los estudios más completos en torno a la problemática hidráulica en la ciudad de México, destacan los realizados por Perló (1989a y 1989b), en ellos se hace un recuento histórico de las principales obras, su localización y los planes y programas en torno a su relación con la toma de decisiones.

Otro enfoque de análisis de los servicios urbanos, más que su caracterización en sí misma, lo encontramos en trabajos como los de Legorreta [1983), Ward (1986, 1989) y Guerrero (1988). Su principal interés es el estudio de las formas de gestión e introducción de servicios en las colonias populares; por su parte, Puente (1988) hace un análisis utilizando la dotación de los servicios como uno de los indicadores para conocer la calidad material de vida de los sectores de bajos ingresos.

\section{Mujer, familia y condiciones de vida}

A pesar de que el tema de la mujer adquirió gran relevancia en esta década, son pocos los trabajos que estudian las característi- 
cas socioeconómicas de la mujer urbana. Kusnir y Largaespada (1986) nos hablan de su participación en la autoproducción de la vivienda en la ciudad de México. Massolo (1983) y Massolo y Díaz (1985) han resaltado el papel de la mujer dentro de los movimientos sociales urbanos. De Oliveira (1989) nos muestra una tipología de ciudades según la participación femenina en los mercados de trabajo, y resalta la existencia de importantes diferencias de participación dependiendo del contexto urbano-regional.

A inicios de los ochenta se elaboraban investigaciones centradas en las condiciones de vida de los sectores populares urbanos (Eckstein, 1982 y Logan, 1981). El tema de crecimiento urbano y segregación fue tratado tanto por Schteingart (1981) como por Cisneros (1981). En la segunda mitad de la década se realizaron numerosos trabajos que se abocaron al estudio de elementos más concretos, como la alimentación, la salud, la morbilidad, etc. [Spindola y Ortiz, 1985; Zúñiga, 1987; Zepeda, 1988; Román Segovia, 1989; De la Peña et al., comps. 1990, y García de Alba et al. 1990).

Impacto socioeconómico de los sismos de 1985

Los sismos de 1985 en la ciudad de México además de sus secuelas destructivas, tuvieron un fuerte impacto social que evidenció una serie de problemas crónicos, sobre todo en su área central. Algunos investigadores académicos se abocaron al estudio de las consecuencias que produjeron; analizaron, por un lado, las nuevas formas que adoptó el movimiento urbano popular y la creación de organizaciones independientes de damnificados demandantes de vivienda (Massolo, 1986; Briseño et al., 1987; Massolo y Schteingart, comps., 1987; Duhau, 1987a y 1987b; Marván y Cuevas, 1987; Cisneros, 1988; Bataillon, 1989). Por otro lado sobresalen aquellos trabajos que evalúan las políticas y los programas de reconstrucción de vivienda, la expropiación de terrenos y los cambios en la tenencia de la tierra (Azuela, 1987; Boils, 1986; Connolly, 1987; Michel M. et al., 1988; Ziccardi, 1986, 1989b). También encontramos análisis sobre el impacto que tuvo el sismo en la industría textil (José Alonso, 1986), en el empleo (Barbieri, 1986 y Morelos, 1987), en el transporte (Camarena, 1986) y en la morbilidad en la ciudad de México (Sánchez y Moreno, 1987). Un debate retomado a partir de los sismos de 1985 fue el de la descentralización de la actividad económica y la población (Bustamante y Delgadillo 1986; Garza, 1986). 


\section{Poder local y municipio}

Los diversos cambios tanto desde el punto de vista de las iniciativas gubernamentales (reformas electorales y constitucionales], como el fortalecimiento de la oposición en México, se vuelven un significativo referente empírico desde el cual se estudian y replantean las ideas en torno a lo municipal y lo local. Uno de los principales trabajos sobre el municipio y los actores políticos es el de Martínez Assad (coord., 1985); también en lo que respecta a las luchas municipales en México y a la conformación de grupos que detentan el poder político local están los trabajos de López Monjardín (1986) y Bassols (1989).

Otra vertiente de trabajos está orientada por el debate que surgió, tanto en Europa como en América Latina, sobre el fortalecimiento de los municipios y las políticas de descentralización (Martínez Assad y Ziccardi, 1986), debate que se enriqueció con la reforma municipal de 1983 (véase Massolo, 1987; Azuela, 1988b; Duhau, 1989 y Melé 1986, 1989).

El tema de la democracia en México se alimentó con los procesos que afloraron a partir de los sismos. De esta manera Tamayo [1988] nos habla de la importancia que tuvo este proceso y la experiencia de las elecciones en 1988 para fortalecer la democracia dentro de los barrios populares.

En torno a las elecciones presidenciales de 1988, en las que se constató un fortalecimiento de la oposición al partido oficial y una movilización desde las bases locales, aparece el trabajo de López Monjardín (1986]. El tema del centralismo político versus el poder local y la identificación de las políticas urbano-regionales, la gestión metropolitana durante la crisis, los nuevos actores en ella y la privatización de los servicios públicos fueron tratados en una obra colectiva, donde el objetivo fundamental fue determinar e] estado del conocimiento sobre estos temas (Coulomb y Duhau, coords., 1988). Sobre el poder local, ilegalidad y urbanización en Puebla, se inscriben los trabajos de Melé (1986, 1989). No obstante la relevancia que tuvo este suceso, aún no se han producido análisis que determinen la manera en que se manifiestan los cambios del consenso político sobre las formas de poder en las ciudades.

\section{Medio ambiente}

A nivel urbano el caso más notable es el de la ciudad de México, que ha alcanzado elevados niveles de contaminación atmosférica que ponen en peligro la salud de sus pobladores. No obstante, 
se han realizado pocos proyectos en torno a esta problemática. Por ejemplo, en los trabajos de Ham, coord. (1983), Jbarra et al. (1984, 1986), se identifican áreas dentro de la ciudad de México con distintas problemáticas ambientales y exponen que lo anterior es reflejo del nivel socioeconómico de la población, de las actividades desarrolladas en las diversas zonas, así como de la configuración geográfica de la ciudad (dirección de vientos, relieve topográfico, etc). Marco del Pont (1984), hace una revisión del fenómeno de la contaminación en relación con la legislación existente. Legorreta y Puente, comps. (1988), presentan una serie de trabajos sobre el avance de la investigación en torno al crecimiento de la ciudad de México y el constante deterioro del medio ambiente y de la calidad de vida de sus habitantes, tocando temas como el de los procesos de expansión urbana en los asentamientos de población de bajos recursos y sus repercusiones en la calidad de vida, la capacidad de la ciudad para la generación de alimentos, los sistemas de distribución comercial, el empleo informal, la problemática del abasto de agua para la ciudad, los niveles de contaminación atmosférica y el impacto que tiene ésta en la salud de los niños.

Se han realizado trabajos más puntuales sobre diversos aspectos críticos de la ciudad de México, entre los que se pueden citar el problema de] agua (Sahab H., 1986; González Ehrlich, 1986), la deforestación del bosque del Ajusco (Haro, 1986), la problemática socioambiental de la basura (Restrepo, 1982; Héctor Castillo, 1990 y Camarena et al., 1987), el transporte y la contaminación del aire (Legorreta y Flores, 1989).

El agravamiento de la contaminación atmosférica en la capital ha intensificado las políticas del gobierno del DDF, por lo que ha diseñado acciones emergentes de corto plazo como el programa Hoy no circula, que sería muy conveniente evaluar con profundidad y estudiar medidas de mediano plazo que tuvieran posibilidades de resolver adecuadamente la situación.

Pocos trabajos han sido elaborados para el caso de otras ciudades; entre ellos encontramos el de Flores (1984) que habla en general de las condiciones ambientales de la ciudad de Guadalajara $y$, en el caso de Coatzacoalcos, Herzing (1987) analiza las consecuencias del deterioro del medio ambiente en los niños.

\section{Las politicas del Estado en torno a lo urbano}

Durante los setenta, el estudio de los planes estatales se centró, fundamentalmente, en el análisis de las políticas habitacionales; 
sin embargo, una década después éste fue superado, pues se amplió, incorporando a los actores involucrados y su impacto -o no- en los procesos de urbanización.

La normatividad de la intervención estatal en los procesos urbanos tiene origen en el establecimiento de la ley General de Asentamientos Humanos (1976) y en el Plan Nacional de Desarrollo Urbano (1978). Posteriormente, en esta década se elaboraron el Plan Nacional de Desarrollo Urbano y Vivienda [Sedue, 1984] y los programas nacionales 1990-1994 de Desarrollo Urbano, de Vivienda y Protección al Medio Ambiente (Sedue, 1990a, 1990b). Estos documentos (exceptuando los últimos tres), así como la serie de iniciativas en torno a la descentralización, la reforma municipal (artículo 115 constitucional), los procesos de regularización de la tenencia de la tierra y las políticas seguidas para la dotación de infraestructura y equipamientos urbanos, se constituyeron en fuente para la elaboración de trabajos encaminados a estudiar las modalidades adoptadas por el Estado para incidir en la organización espacial.

Las principales líneas de investigación tienen por objeto evaluar los avances de la planeación en México, el papel que juegan dentro de la política del Estado, las inconsistencias entre la acción y el plan y la dificultad de consolidar los intereses de los diversos actores urbanos (Garza, comp., 1989). El carácter normativo de los planes y la falta de lineamientos tendientes a influir en las causas que determinan la distribución espacial económico-demográfica, son vistos como las principales limitantes la planeación para modificar la organización territorial. En Garza y Puente (1989) se analizan las incongruencias internas entre los objetivos y las estrategias contenidas en el Plan Nacional de Desarrollo Urbano 1978. Los autores concluyen que a pesar de que no tuvo impacto en la organización territorial, marcó el inicio de la participación planificada del Estado en los procesos de urbanización. Conolly (1989b), por su parte, contrasta los planteamientos en materia de descentralización contenidos en el Plan Nacional de Desarrollo Urbano y Vivienda (1984-1988) y las tendencias de crecimiento de las ciudades intermedias y de las carencias en materia de infraestructura; en consecuencia, afirma que su evolución responde más a las condiciones socioeconómicas determinadas históricamente y no a objetivos contenidos en un plan y que, en cierta medida, son contradictorios.

Estos trabajos son analizados considerando los fundamentos teóricos de la planeación y las concepciones económico-sociales que subyacen en éstos, tema tratado a profundidad por Iracheta (1988b).

La política de parques industriales se constituyó en uno de los 
principales instrumentos de descentralización económica utilizados por el Estado para incidir en la organización interurbana nacional. Sin embargo, su impacto fue menor de lo que se esperaba, y por ende las inversiones, en algunos casos, fueron exitosas [Garza, 1988). Se realizaron también otros trabajos en los cuales se intentó hacer un balance de las políticas implementadas en el periodo de crisis, que buscaban la ordenación del territorio (Garza, 1986b; Jacobs y Ziccardi, 1984).

A nive] intrametropolitano tenemos, en primer término, a aquellos estudios que se refieren al financiamiento de las ciudades como una de las políticas urbanas que influyen en la urbanización y concentración económico-poblacional, sobre todo en la Zona Metropolitana de la Ciudad de México (Connolly, 1984 y 1989; Pírez, 1984; Perló 1981). En segundo lugar se analizó la política de dotación de servicios urbanos, considerando la gestión y organización de las instituciones involucradas y el papel de la movilidad popular (Ward, 1986, 1990). La relación entre las modificaciones observadas en la forma de gestión urbana y la institucionalización de la planeación es analizada por Duhau (1988a, 1989).

Por último, la crítica que se ha realizado a los instrumentos de planeación no sólo se basa en sus aspectos técnicos, sino en sus incongruencias jurídico-administrativas. Azuela (1989) realiza una crítica en torno a la evolución del régimen legal de la planeación, desde el punto de vista de las implicaciones que tiene el tipo de propiedad del suelo sobre el desarrollo urbano; así, resalta que el mayor nivel de complejidad en el uso del suelo se presenta en los terrenos ejidales y comunales, sujetos a fuertes procesos de expansión ilegal urbana. Otra dificultad señalada por el autor es la distribución de competencias de los diferentes niveles de gobierno, en donde no se han respetado, por razones de poder político, las atribuciones otorgadas a partir de la reforma municipal al artículo 115 constitucional en 1983. Sobre este mismo tema, Massolo (1989) hace un análisis sobre las posibles implicaciones de dicha reforma y la limitada capacidad técnico-financiera de los gobiernos municipales para tomar en sus manos el desarrollo urbano local.

Lo realizado hasta ahora es claramente insuficiente y se requiere impulsár significativamente la investigación concreta de las políticas urbano-regionales del Estado mexicano. Esto ayudaría a resolver las fuertes limitaciones de la planeación territorial del país, aunque también sería conveniente desarrollar estudios que sistematicen y desarrollen las técnicas y teorías existentes sobre la planificación espacial (G. Garza, 1986). 


\section{Conclusiones}

Puede afirmarse que los cambios socioeconómicos y políticos de los ochenta y sus diversas coyunturas tuvieron un importante impacto en las temáticas de investigación; sin embargo, sería recomendable que en el futuro se realicen esfuerzos de profundización. Ahora bien, la compleja articulación que se ha dado entre los procesos urbanos del país, las percepciones por los diversos sectores sociales sobre cuáles son los "problemas urbanos" y la tendencia por parte de] sector académico a la importación de teorías (neoclásicas o marxistas), han desembocado en una práctica de investigación que si bien no ha cuestionado a profundidad los planteamientos sobre la urbanización capitalista, sí ha explorado los "viejos" y "nuevos" temas enriqueciendo el análisis empírico.

Cabe reconocer que algunos trabajos, sobre todo los de la primera mitad de la década, se refieren a temáticas que se generaron en los setenta. No obstante, los que se refieren a los ochenta ya visualizaban (en la mayoría de los casos en forma hipotética) las implicaciones de la crisis sobre la sociedad y el territorio. Este tema está aún poco explorado, siendo necesario continuar su análisis.

Probablemente los estudios realizados en los noventa, estarán enfocados al estudio de las repercusiones sociales y económicas de la crisis. Ejemplo de ello sería el ritmo de creciniento industrial por ciudades y regiones; los cambios en la estructuración espacial de la actividad económica y de la población, en relación con las estrategias explícitas o no del desarrollo nacional; el papel económico y las tasas de crecimiento de las ciudades medianas y pequeñas y su relación con el desarrollo microrregional; formas de financiamiento de programas y la aplicabilidad de la planificación urbana; las consecuencias de la reducción de la intervención de Estado en la economía y la tendencia a la terciarización de la economía.

Actualmente se abre la interrogante de cuáles han sido las modificaciones territoriales a partir de la apertura económica hacia los mercados internacionales y las que se darán con la firma del Tratado de Libre Comercio, que seguramente provocará cambios importantes sobre todo en lo que se refiere a la dinámica de la frontera norte dentro de la economía nacional, los flujos migratorios y los subsecuentes problemas urbanos.

Se distingue también la necesidad de realizar estudios más profundos sobre las condiciones de vida de la población en lo que se refiere a alimentación, salud, la ciudad y los niños, repercusiones ambientales, etc. Asimismo, se requiere analizar las formas de expansión urbana, la participación popular y el poder local, y la subsecuente lucha por la democracia, que si bien ya han sido estu- 
diados con anterioridad, precisan de una mayor atención desde la perspectiva urbano-regional.

Sin embargo, pasará mucho tiempo para que se logre superar la dependencia de métodos y técnicas desarrolladas en los países hegemónicos y aspirar a descubrir muevas técnicas, categorias y conceptos que enriquezcan la investigación de las características y determinantes de la organización del espacio territorial en México, aunque se puede constatar que en la última década han surgido nuevos objetos de estudio dentro de los análisis urbanos.

\section{Bibliografía}

Aguilar Díaz, Miguel Angel (1988), "Movimientos urbanos y psicología social", en Politica y movimientos sociales en la Ciudad de México, México. Ed. Plaza y Valdés, Departamento del Distrito Federal, Colecc. Desarrollo Urbano. Desafíos de una gran Metrópoli, pp. 127-141.

Alba Vega, Carlos y Dirk Kruijt (1988), Los empresarios y la industria de Guadalajara, México, El Colegio de Jalisco.

Aldrete-Hass, José A. (1985), "Asentamientos ilegales, políticas urbanas y el Estado", en Estudios Sociológicos, vol. III, núm. 8, mayo-ago., El Colegio de México, pp. 371-387.

Alonso, Jorge (1980), Lucha urbana y acumulación de capital, México, Ediciones de la Casa Chata.

(comp.) (1986), Los movimientos sociales en México, México, Ediciones de la Casa Chata.

Alonso, José A. (1986), "Industria textil y catástrofe urbana", en Revista Mexicana de Ciencias Políticas y Sociales, nueva época, año XxXII, núm. 123, ene.-mar., UNAM, pp. 81-88.

Arau Chavarrfa, Rosalinda (1987), "Organización de los pueblos y colonias del Sur", en Revista Mexicana de Sociología, vol. XLIX, núm. 4, oct.-dic., pp. 9-35.

Arias, Patricia (1985), Guadalajara, la gran ciudad de la pequeña industria, México, El Colegio de Michoacán.

Arroyo Alejandre, Jesús (1988), "Impactos de los incentivos fiscales en la desconcentración industrial metropolitana: el caso de Jalisco", en Estudios Demográficos y Urbanos, vol, 3, núm. 1, ene.-abr., El Colegio de México, pp. 163-179.

y Guillermo de la Peña [1990), "La migración hacia Guadalajara: algunas comparaciones de la Encuesta de Hogares de 1972 y 1986", en Crisis, conflicto y sobrevivencia. Estudio sobre la sociedad urbana en México, Gúadalajara, Universidad de Guadalajara-CIESAS, pp. 25-54.

Azuela, Antonio (1982), "El desarrollo urbano y la función social de la propiedad", en Revista "A" (Revista de Ciencias Sociales y Humanidades), vol. III, núm. 5, División de Ciencias Sociales y Humanidades, UAM-Azcapotzalco, pp. 65-84.

(1984), "Hacia una sociología jurídica de la urbanización popu- 
lar", en Revista "A" (Revista de Ciencias Sociales y Humanidades), vol. v, núm. 11, División de Ciencias Sociales y Humanidades, UAMAzcapotzalco, pp. 93-112.

(1987), "De inquilinos a propietarios. Derecho y política en el Programa de Renovación Habitacional Popular", en Estudios Demográficos y Urbanos, vol. 2, núm. 1, ene.-abr., El Colegio de México, pp. 53-73. (1988a), "Obedézcase pero no se cumpla. La reforma municipal y el régimen local de la gestión urbana", en Alegatos, núm. 10, septiembre-diciembre.

[1988b], "El marco jurídico de la vivienda", en Procesos habitacionales en la Ciudad de México, México, Sedue-UAM, Col. Cuadernos Universitarios, núm. 51, pp. 43-62.

[1989a], La ciudad, la propiedad privada y el derecho, México, El Colegio de México, Centro de Estudios Demográficos y de Desarrollo Urbano.

(1989b), "E] significado jurídico de la planeación urbana en México", en Una década de Planeación Urbano-Regional en México, 19781988, México, El Colegio de México, pp. 55-77.

et al. (1989c), "La institucionalización de las colonias populares y la política urbana en la Ciudad de México 1940-1946”, en Revista Sociológica, ene.-abr., pp. 111-133.

Ball, M. and P. Connolly (1987), "Capital acumulation, in the Mexican construction industry 1930-1982", en International Journal of Urban Regional Research, vol. 11, núm. 2, junio, Londres, pp. 153-171.

Barba de Piña Chan, Beatriz (1985), La magia y el indligena en el Distrito Federal, México, InAH.

Barbieri, M. Teresita de (1986), "Los damnificados y el empleo [sismo 1985)", en Revista Mexicana de Sociología, vol. xLvill, núm. 2, abr.jun., UNAM, pp. 59-102.

Bassols, Mario (1989), "Las estructuras políticas locales frente al centralismo de la planeación urbana y regional", en R. Coulomb y E. Duhau (coords.), Políticas urbanas y urbanización de la política, México, UAM-Azcapotzalco, pp. 35-43.

Bataillon, Claude (1989), "El terremoto de la ciudad de México: balance a mediano plazo", en Revista Mexicana de Sociología, año LI, núm. 2, abr.-jun., pp. 473-480.

Bazant, Jan (1985), Autoconstrucción de vivienda popular, México, Ed. Trillas-Centro de Ecodesarrollo.

Bejarano, Fernando (1983), "Las irregularidades de la tenencia de la tierra en las colonias populares (1976-1986]", en Revista Mexicana de Sociología, vol. 45, núm. 3, jul.-sept., pp. 797-827.

Benítez Zenteno, Raúl y José Benigno Morelos (comps.) (1988), Grandes problemas de la Ciudad de México, México, Ed. Plaza y Valdés, Departamento del Distrito Federal, Colecc. Desarrollo Urbano, Desafíos de una gran Metrópoli.

Bennett, Vivienne (1988), "Servicios públicos urbanos y conflicto social: el agua en Monterrey", en Monterrey. Siete estudios contemporáneos, Monterrey, Universidad Autónoma de Nuevo León, pp. 209-246. 
Boils, Guillermo (1986), "Sismo y política habitacional", en Revista Mexicana de Ciencias Políticas y Sociales, nueva época, año XXxiI, núm. 123, ene.-mar., UNAM, pp. 47-57.

Brambila Paz, Carlos y Héctor Salazar [1984], "Concentración y distribución de los tamaños de ciudades en México: 1940 a 1980", en Demografía y Economía, vol. xvili, núm. 1-57, El Colegio de México, pp. 48-85.

Bustamante Lemus, Carlos (1983), Urban concentration and policies for descentralization in Mexico 1976-1982. México, UNAM, Instituto de Investigaciones Económicas.

y Javier Delgadillo Macías (1986), "Terremoto y descentralización. Oportunidad para un nuevo proyecto nacional", en Problemas del Desarrollo, vol. XVI, núm. 62/63, UNAM, Instituto de Investigaciones Económicas, pp. 75-91.

Calderón Cockburn, Julio [1987), "Luchas por la tierra, contradicciones sociales y sistema político. El caso de las zonas ejidales y comunales en la Ciudad de México [1980-1984]", en Estudios Demográficos y Urbanos, vol. 2, núm. 2, mayo-ago., El Colegio de México, pp. 301-324.

Camarena, Margarita [1986), "Desastre y transporte en la Ciudad de México, en Revista Mexicana de Ciencias Políticas y Sociales, nueva época, año XXxII, núm. 123, ene.-mar., UNAM, pp. 39-45.

[1987], "El transporte de carga en el Valle de México", en México: problemas urbano-regionales, México, Ed. García Valdés, Instituto de Investigaciones Sociales, (INAM, pp. 145-176.

Héctor Castillo y Alicia Ziccardi (1987), "Basura: procesos de trabajo e impactos en el medio ambiente urbano". en Estudios Demográficos y Urbanos, vol. 2, núm. 3, sept.-dic., El Colegio de México, pp. 513-543.

Castañeda, Víctor y Diana Villarrea] (1986). Urbanización y autoconstrucción de vivienda en Monterrey. México, Centro de Ecodesarrollo.

Castillo, Héctor (1987), "Problemas y perspectivas recientes del abasto de alimentos en la Ciudad de México", en México: problemas urbanoregionales, México, Ed. García Valdés, Instituto de Investigaciones Sociales, INAM, pp. 93-108.

(1990). La sociedad de la basura. caciquismo en la Ciudad de México, 2a. ed., México, Instituto de Investigaciones Sociales, UNAM, Cuadernos de Investigación Social.

Castillo, Jaime [coord.] [1986], Los movimientos sociales en Puebla, Puebla, Departamento de Investigaciones arquitectónicas y urbanísticas. Instituto de Ciencias Universidad Autónoma de Puebla, 2 v.

Cerutti, Mario (1982). "La formación de capitales preindustriales en Monterrey 1850-1890". en Revista Mexicana de Sociología, año 44, núm. 1. ene.-mar., pp. 81-117.

(1983), "Burguesía y capitalismo en Monlerrey (1850-1910) en Revista Claves Latinoamericanas.

(coord.) (1987). Monterrey. Nuevo León, el noreste. Siete estudios históricos, Monterrey. Universidad Autónoma de Nuevo León. Facultad de Filosofía y leetrass. 
(coord.) (1988), Monterrey. Siete estudios contemporáneos, Monterrey, Universidad Autónoma de Nuevo León, Facultad de Filosofía y Letras.

Cisneros, Armando (1981), "Suelo urbano y segregación social", en Revista Habitación, núm. 2-3, sept.

(1988), "La reconstrucción habitacional de la Ciudad de México. Apuntes para un balance", en A. Cisneros (coord.) Rescate y reconstrucción del centro de la Ciudad de México, enero.

Connolly, Priscilla (1980), Asentamientos no controlados y autoconstrucción ¿qué tipo de solución?. México, Ed. Autogobierno, núm. 11.

(1984), "Finanzas públicas y Estado local: e] caso del Departamento del Distrito Federal", en Revista "A" (Revista de Ciencias Sociales y Humanidades), vol. v, núm. 11, UAM-Azcapotzalco, pp. 57-92.

(1987), "La política habitacional después de los sismos", en Estudios Demográficos y Urbanos, vol. 2, núm. 1, ene.-abr., El Colegio de México, pp. 101-120.

(1988a), "Crecimiento urbano, densidad de población y mercado inmobiliario", en Revista "A" (Revista de Ciencias Sociales y Humanidades), vol. IX, núm. 25, pp. 61-86.

(1988b), "La industria de la construcción y las relaciones de trabajo en la producción habitacional de la Ciudad de México", en M. Michel [coord.], Procesos habitacionales en la Ciudad de México. México, UAM-Sedue, pp. 182-220.

(1989a), "Finanzas públicas de la Ciudad de México", en M. Schteingart (coord.), Las ciudades latinoamericanas en la crisis, México, Ed. Trillas, pp. 149-162.

(1989b) "Programa Nacional de Desarrollo Urbano y Vivienda, 1984: ¿desconcentración planificada o descentralización de carencias?", en Una década de Planeación Urbano-Regional en México. 1978-1988, México, El Colegio de México, pp. 103-120.

(1990), "Dos décadas de "sector informal", en Revista Sociológica, UAM-Azcapotzalco, año 5, núm. 12, ene.-abr., pp. 75-94.

Contreras, Wilfrido (1988), "El agua, ¿recurso renovable?", en Sergio Puente y ]. Legorreta (coords.), Medio ambiente y la calidad de vida, México, Ed. Plaza y Valdés, Departamento de] Distrito Federal, pp. 251-262.

Coulomb Bosc, René (1985), "La vivienda de alquiler en las áreas de reciente urbanización", en Revista "A" (Revista de Ciencias Sociales y Humanidades), vol. vı, núm. 15, UAM-Azcapotzalco, pp. 43-69.

(1987), La legjslación en materia de vivienda en arrendamiento para el Distrito Federal, 2a. ed., México, C:ENvı, Colecc. Cuadernos del Ci:i'l núm. 3.

[1988], "Vivienda en renta y dinámica habitacional en la Ciudad de México", en M. Michel [coord.), Procesos habitacionales en la Ciudad de México, México, Uam-Sedue, pp. 141-182.

y E. Duhau (coords.) [1988), La ciudad y sus actores. Conflictos y estrategias socioespaciales frente a las transformaciones de los centros urbanos. México. I'Airifal. 
Cruz Rodríguez, Ma. Soledad (1989). "El deterioro ecológico de] Valle de México. Un problema histórico", en Revista "A" (Revista de Cienicias Sociales y Humanidades), vol. IX, num. 2b, ene.-abr., WAN-A\%capotzalco, pp. 3-12.

Davis, D.E. (1981), "Migration, rank-size distribution and economic development: the case of Mexico", en Studies in Comparative International Development, vol. 10, núm. 3-4, New Brunswick. N.J.

Delgado, Javier (1988), "El patrón de ocupación territorial de la Ciudad de México al año 2000". en Estructura territorial de la Ciudad de México. México, Ed. Plaza y Valdés, Departamento del Distrito Federal, Col. Desarrollo Urbano. Desafíos de una gran Metrópoli, pp. 101-142. (1990), "De los anillos a la segregación. La ciudad de México, 19501987", en Estudios Demográficos y Urbanos, vol. 5, núm. 2-14, mayoago., El Colegio de México, pp. 237-274.

Duarte Ortega, Nicolás (1988), "La estatización del agua en Monterrey", en Monterrey. Siete estudios contemporáneos, Monterrey, Universidad Autónoma de Nuevo León, pp. 181-208.

Duhau, Emilio [1982), "Agricultura y desarrollo urbano en la Nueva España", en Investigación Económica, vol. Xl.,, núm. 162, oct.-dic., ILE-UNAM, pp. 85-100.

[1987a), "La formación de una política social: e] caso del Programa de Renovación Habitacional Popular en la Ciudad de México", en Estudios Demográficos y Urbanos, vol. 2, núm. 1, ene.-abr., El Colegio de México, pp. 75-100.

(1987b), "Mercado interno y urbanización en el México colonial", tesis de maestria en desarrollo urbano, México, El Colegio de México.

(1988a), "Política habitacional para los sectores populares en México. La experiencia de FONHAPO", en Medio ambiente y urbanización, año 7, sept., Buenos Aires, Cl.Acso.

[1988b], "Planeación metropolitana y política urbana municipal en la Ciudad de México", en Estudios Demográficos y urbanos, vol. 3. núm. 1, E] Colegio de México, pp. 115-142.

(1989a), "Las instancias locales de gobierno y la planeación de la zona metropolitana de la Ciudad de México", en Gustavo Garza (comp.), Una década de planeación urbano-regional en México, 19781988, México, El Colegio de México, pp. 349-385.

(1989b), "Las instancias locales de gobierno y la planeación de la Zona Metropolitana de la Ciudad de México" en Una Década de Planeación Urbano-Regional en México 1978-1988, México, El Colegio de México, pp. 349-372.

Durand, Jorge (1983), La ciudad invade al ejido, México, Ediciones de la Casa Chata.

Eckstein, Susan (1982), El estado y la pobreza urbana en México, México, Siglo XXI Editores.

Escobar, Agustín (1986), Con el sudor de tu frente: mercados de trabajo y clase obrera en Guadalajara, Guadalajara, El Colegio de Jalisco. y Mercedes G. de la Rocha (1988), "Microindustria, informalidad y crisis en Guadalajara. 1982-1987”, en Estudios Sociológicos, vol. 
VII, núm. 18, sept.-dic., El Colegio de México, pp. 553-581.

Figueroa, Óscar (1990), "La evolución de las políticas de transporte urbano colectivo en la Ciudad de México entre 1965 y 1988", en Estudios Demográficos y Urbanos, vol. 5, núm. 2-14, mayo-ago., El Colegio de México, pp. 221-235.

Flores Tritschler, Enrique (1984), Guadalajara: el medio ambiente. Investigación 1900-1984, Guadalajara, Universidad de Guadalajara.

García, Brigida et al. (1982), Hogares y trabajadores en la Ciudad de México, México, El Colegio de México, UNAM.

Garcia de Alba, Javier, Elva Arias Merino, Ana Miranda Macias y Ana Martínez Mesa (1990), "Morbilidad y mortalidad en la zona metropolitana de Guadalajara", en Crisis, conflicto y sobrevivencia. Estudio sobre la sociedad urbana en México, México, Universidad de Guadalajara-cIESAS, pp. 207-228.

García Lascurain, María [1988), "Calidad de vida en la periferia de la Zona Metropolitana de la Ciudad de México", en Puente y Legorreta [coords.), Medio ambiente y calidad de vida, México, Ed. Plaza y Va]dés, Departamento del Distrito Federal, pp. 109-136.

García Peralta, Beatriz (1986), "La lógica de las grandes acciones inmobiliarias en la ciudad de Querétaro", en Estudios Demográficos y Urbanos, vol. 1, núm. 3, sept.-dic., El Colegio de México, pp. 375-397. (1989), "Mercado de tierra y actividad inmobiliaria en la ciudad de Guadalajara (primera aproximación)", en Proceedings of the 10th Bartlett International Summer School. y Manuel Perló [1984], "Estado, sindicalismo oficial y políticas habitacionales. Análisis de una década de Infonavit", en El desarrollo urbano en México, problemas y perspectivas, México, Programa Universitario Justo Sierra, UNAM, pp. 131-160.

Garza, Gustavo (1980), Industrialización de las principales ciudades de México, México, El Colegio de México. (1983), "Desarrollo económico, urbanización y políticas urbanoregionales en México (1900-1982)", en Demografía y Economía, vol. XVII, núm. 1-54, El Colegio de México, pp. 157-180. (1985), El proceso de industrialización de la Ciudad de México, 1821-1970, México, El Colegio de México.

(1986a), "Ciudad de México: dinámica industrial y perspectivas de descentralización después del terremoto", en Blanca Torres (comp.), Descentralización y democracia en México, México, El Colegio de México, pp. 219-236. (1986b), "Planeación urbana en México en periodo de crisis [19831984]", en Estudios Demográficos y Urbanos, vo]. 1, núm. 1, ene.-abr., El Colegio de México, pp. 73-96.

(1988), "La política de parques y ciudades industriales en México: etapa experimental (1953-1970)", en Estudios Demográficos y Urbanos, vol. 3, núm. 1, ene.-abr., El Colegio de México, pp. 39-55. (comp.) (1989), Una década de planeación urbano-regional en México, 1978-1988, México, El Colegio de México. y Programa de Intercambio Científico y Capacitación Técnica. 
DDF (comps.) (1.987), Atlas de la Ciudad de México, México, Departamento del Distrito Federal, El Colegio de México.

y Sergio Puente (1989), "Racionalidad e irracionalidad de la política urbana en México: el plan nacional de desarrollo urbano, 1978", en Una década de planeación urbano-regional en México, 1978-1988, México, El Colegio de México, pp. 79-102.

y Martha Schteingart (1984), "Ciudad de México: dinámica industrial y estructuración del espacio en una metrópoli semi-periférica", en Demografía y Economía, vol. xviII, núm. 4-60, El Colegio de México, pp. 581-604.

y Luis ]. Sobrino (1989), Industrialización periférica en el sistema de ciudades de Sinaloa, México, El Colegio de México.

Gilbert, Alan (ed.) (1989), Hausing and Land in Urban Mexico, San Diego, Center U.S. Mexican Studies, University of California, Col. Monograph Series, 31.

Giner de los Ríos, Francisco (1990), "Una tipología para el análisis de microindustrias", en Crisis, conflicto y sobrevivencia. Estudio sobre la sociedad urbana en México, México, Universidad de GuadalajaraCIESAS, pp. 151-156.

Gliemann, Nélida [1987), "Bandas juveniles: un enfoque en la investigación en Querétaro", en Revista Sociología, núm. 1, Querétaro, Universidad Autónoma de Querétaro.

González de Alba, J.igia (1984), "J,as ciudades pequeñas y medianas dentro de un sistema urbano nacional. El caso de México", en Revista Interamericana de Planificación, vol. 18, núm. 71, pp. 84-95.

González de la Rocha, Mercedes (1986), "Lo público y lo privado: el grupo doméstico frente al mercado de trabajo urbano", en Cambio regional, mercado de trabajo y vida obrera en Jalisco, Guadalajara, El Colegio de Jalisco, Col. Estudios Sociales núm. 1.

Gonæález Ehrlich, Erika (1986), "El agua se va para no volver. El subsuelo del Valle de México". en Información Científica y Tecnológica, vol. 8, núm. 112, enero.

Gortari, Rabiela Hira de [1982], "Los años difíciles, una economía urbana: el caso de la Ciudad de México, [1890-1910)", en Revista Iztapalapa. año 3, núm. 6, ene.jun., liAM-Iztapalapa, pp. 101-114.

y Regina Hernández Franyuti (comps.) (1988a), La ciudad de México y el Distrito Federal; una historia compartida, México, Departamento del Distrito Federal, Instituto de Investigaciones Doctor José María Luis Mora.

(comps.) (1988b), Memoria y encuentros. la Ciudad de México y el Distrito Federal (1824-1928). México, Departamento del Distrito Federal, Instituto de lnvestigaciones Doctor José María Luis Mora.

Graizbord, Boris, (1984b) "Perspectivas de una descentralización del crecimiento urbano en el sistema de ciudades de México", en Revista Interamericana de Planificación, vol. 18, núm. 71, pp. 36-58.

Guerrero Reyes, J,ourdes (1988). "Problemas de servicios urbanos en colonias populares". en Zenteno y Morelos (comps.). Grandes problemas de la Ciudud de México. México. Ed. Plaza y Valdés. Departi- 
mento del Distrito Federal, pp. 131-184.

Gutiérrez de MacGregor, María Teresa et al. (1983), El problema del transporte urbano en la Ciudad de México, México, UNAM, Instituto de Geografía.

Ham Chande, Roberto (coord.) (1983), La ciudad y el medio ambiente; el caso de la Zona Metropolitana de la Ciudad de México, México, El Colegio de México, Centro de Estudios Demográficos y de Desarrollo Urbano.

Haro Sánchez, Margarita Yolanda (1986), Causas y consecuencias del deterioro ecológico del bosque del Ajusco en la Delegación Tlalpan, D. F., México, UNAM, Facultad de Filosofía y Letras, Col. Geográfica.

Herzig, Mónica [1987], El niño y el medio ambiente, México, Centro de Ecodesarrollo, Col. Serie Medio Ambiente.

Hiernaux, Daniel [1986), Urbanización y autoconstrucción de vivienda en Tijuana, México, Centro de Ecodesarrollo.

(1989), "La planeación de la Ciudad de México: logros y contradicciones", en Una década de planeación urbano-regional en México. 1978-1988, México, El Colegio de México, pp. 235-254.

Ibarra, Valentín (1981). "La acción estatal en el transporte de personas", en Habitación, núm. 2-3, Fovissste.

[1983), "La producción del servicio de autotransporte en el área urbana de la Ciudad de México", en Demografía y Economía, vol. XVII, núm. 1-53, E] Colegio de México, pp. 38-59.

, Sergio Puente y Martha Schteingart [1984], "La ciudad y el medio ambiente", en Demografía y Economía, vol. xvıII, núm. 1-57, El Colegio de México, pp. 110-143.

, S. Puente y Fernando Saavedra (comps.) (1986), La ciudad y el medio ambiente en América Latina, México, El Colegio de México.

I racheta, Alfonso (coord.) (1983), La situación del transporte urbano en las áreas metropolitanas del Estado de México, Toluca, Méx., División de Posgrado de la Facultad de Arquitectura y Arte, Universidad Autónoma del Estado de México.

[coord.] (1984), El suelo urbano. recurso estratégico para el desarrollo urbano, Toluca, Méx.. División de Posgrado de la Facultad de Arquitectura y Arte, Universidad Autónoma del Estado de México. (1988a), "Algunas reflexiones en relación al problema del suelo para vivienda en la Zona Metropolitana de la Ciudad de México", en Procesos habitacionales en la Ciudad de México, México, SedueUAM, Col. Cuadernos Universitarios, núm. 51, pp. 63-104.

(1988b), "Los problemas del suelo y la política urbana en la Zona Metropolitana de la Ciudad de México", en Grandes problemas de la Ciudad de México, México, Ed. Plaza y Valdés, Departamento del Distrito Federal, Col. Desarrollo Urbano. Desafíos de una gran metrópoli. pp. 47-96.

y Alberto Vi]lar Calvo [coords.] [1988], Política y movimiento sociales en la Ciudad de México. México, Ed. Plaza y Valdés, Departamento del Distrito Federal. Col. Desarrollo Urbano. Desafíos de una gran metrópoli. 
Jacobs, M. y A. Ziccardi [1984], "La polftica de ordenamiento territorial en México: desconcentración y crisis", en Revista Interamericana de Planificación, vol, xvill, núm. 71, septiembre, pp. 178-185.

Jusidman, Clara (1988), "Empleo y mercados de trabajo en el área metropolitana de la Ciudad de México 1975-1988", en Puente y Legorreta (coords.), Medio ambiente y calidad de vida, México, Plaza y Valdés/DDF, pp. 225-250.

Kandell, Jonathan (1990), La capital, la historia de la Ciudad de México, México, Javier Vergara editor.

Kusnir, Liliana y Carmen Largaespada (1986), "Women's participation in self-help housing projects in Mexico City", en Marianne Schmink et. al. (eds.), Learning about women. ... New York, Population Council, pp. 84-100.

Lailson, Silvia (1990), "Las obreras en sus hogares", en Crisis, conflicto y sobrevivencia. Estudio sobre la sociedad urbana en México, México, Universidad de Guadalajara-CIESAS, pp. 399-414.

Lau, Rubén [1986], "Ciudad Juárez: grupos de presión y fuerzas polítjcas", en Rubén Lau et al., Sistema político y democracia en Chihuahua, Cd. Juárez, México, Universidad Autónoma de Ciudad JuárezIIS-UNAM.

Legorreta, Jorge (1983), El proceso de urbanización en ciudades petroleras, México, Centro de Ecodesarrollo.

(1984), La autoconstrucción de vivienda en México: El caso de las ciudades petroleras, México, Centro de Ecodesarrollo.

y Sergio Puente (coords.) (1988), Medio ambiente y calidad de vida, México, Ed. Plaza y Valdés, Departamento del Distrito Federal, Col. Desarrollo Urbano. Desafíos de una gran Metrópoli.

y Ángeles Flores (colaboradora) (1989), Transporte y contaminación en la Ciudad de México, México, Centro de Ecodesarrollo.

Levi de López, Silvana et al. (1981), "Estructura y desarrollo del distrito comercial y de servicios en el área central de la Ciudad de México", en Boletín de la Sociedad Mexicana de Geografía y Estadistica, tomo 128, México.

Lira, Andrés (1983), Comunidades indígenas frente a la Ciudad de México, México, El Colegio de Michoacán.

Logan, Kathleen (1981), "Getting by with less: economic strategies of lower income household in Guadalajara", en Urban Antropology, vol. 10, núm. 3.

Lomnitz, L. (1985), "A model of the power structure of urban Mexico", en Comparative Urban Research, USA, vol. 11, núm. 1-2.

López Monjardín, Adriana (1986), La lucha por los ayuntamientos, una utopía viable, México, Siglo XXI Editores.

López Rangel, Rafael [1987), Urbanización y vivienda en Guadalajara, México, Centro de Ecodesarrollo.

Marco del Pont, Luis (1984), El crimen de la contaminación, México, Universidad Autónoma Metropolitana.

Martínez Assad, Carlos (coord.) (1985), Municipios en conflicto, México, GV Editores-IIS-UNAM. 
y A. Ziccardi (1986), "El municipio entre el estado y la sociedad", en Revista Mexicana de Sociología, vol. XLviIl, núm. 4, oct.-dic., pp. 7-50.

Marván, Ignacio y Aurelio E. Cuevas (1987), "El movimiento de damnificados de Tlaltelolco (septiembre de 1985-marzo de 1986), en Revista Mexicana de Sociología, vol. XLIX, núm. 4, oct.-dic., México, pp. 111140.

Massolo, Alejandra (1983), "Las mujeres en los movimientos sociales urbanos en la Ciudad de México", en Revista Iztapalapa, núm. 9, UAM, pp. 152-167.

[1986], "Que el gobierno entienda, lo primero es la vivienda", en Revista Mexicana de Sociología, vol. xL, núm. 2, México, pp. 195238.

(1987), "La corriente hacia abajo: descentralización y municipio", en Revista Mexicana de Ciencias Políticas y Sociales, núm. 128, México, UNAM, pp. 101-128.

(1989), "La descentralización de la gestión pública en México: la reforma municipal de 1983", en G. Garza (comp.), Una década de planeación urbano-regional en México, 1978-1988, México, El Colegio de México, pp. 121-151.

y Lucila Díaz Romer (1985) "Consumo y lucha urbana en la Ciudad de México: mujeres protagonistas", en Revista "A" (Revista de Ciencias Sociales y Humanidades), vol. 6, núm. 15, mayo-ago., UAMAzcapotzalco, pp. 135-151.

y Martha Schteingart (comps.) [1987), Participación social, reconstrucción y mujer. El sismo de 1985, México, El Colegio de MéxiCO, UNICEF.

Melé, Patrice (1986), "Poder local y urbanización en la ciudad de Puebla", en J. Padua y A. Vanneph (comps.), Poder local, poder regional, México, El Colegio de México-CEMCA, pp. 222-245.

(1989), "Crecimiento urbano, ilegalidad y poderes locales en la ciudad de Puebla", en Estudios Demográficos y Urbanos, vol. 4, núm. 2, mayó-ago., México, El Colegio de México, pp. 281-312.

Méndez Main, Silvia (1990), "El sector informal en dos ciudades de la frontera norte: Tijuana y Ciudad Juárez", en Crisis, conflicto y sobrevivencia. Estudio sobre la sociedad urbana en México, México, Universidad de Guadalajara, pp. 181-198.

Mercado, Ángel (1988), "La ciudad de Masas", en Política y movimientos sociales en la Ciudad de México, México, Ed. Plaza y Valdés, Departamento del Distrito Federal, Col. Desarrollo urbano. Desafíos de una gran metrópoli, pp. 171-183.

(1989), Arturo Loppe López, gestor urbano, México, UAMXochimilco, División de Ciencias y Artes para el Diseño.

Merla Rodríguez, Gerardo (1983), "Problemática actual del crecimiento geo-demográfico de Monterrey y su área metropolitana", en Memoria del Noveno Congreso Nacional de Geografía, Guadalajara, Jal.

(1986), Monterrey, integración regional del área metropolitana, 1940-1985, Monterrey, N.L., Gobierno del Estado de Nuevo León, Se- 
cretaría de Administración, Archivo General del Estado, Col. Cuadernos del Archivo núm. 7.

Michel, Marco A. (coord.) (1988), Procesos habitacionales en la Ciudad de México, México, Sedue-UAM, Col. Cuadernos Universitarios, núm. 51. , José L. Mecatl y Alicia Ziccardi Contigiani (1988), Cạsa a los damnificados. Dos años de política habitacional en la reconstrucción, México, IIS-UNAM.

Mier y Terán, A. (1982), "Expansión de la metrópoli en el Valle de México", en Revista Habitación, núm. 718, México, Fovissste.

y Alicia Ziccardi (1985), "Autoconstrucción y acción pública", en Revista Vivienda, núm. 1, México, pp. 48-67.

Moctezuma, Pedro (1981), "Las luchas urbano-populares en la coyuntura actual", en Teoría y Política, año II, núm. 5, julio-septiembre, México, pp. 101-124.

(1984a), "El movimiento urbano popular mexicano", en Nueva Antropología, vol. 6, núm. 24, junio.

[1986), "La Coordinadora Nacional del Movimiento Urbano Popular en el Valle de México", en Los movimientos sociales en el Valle de México, México, CIESAS-INAH.

y Bernardo Navarro (1984b), "Proletariado, estado y reproducción de la fuerza de trabajo en las colonias populares", en Nueva Antropología, vol. 6, núm. 24, México.

y B. Navarro (1989), La urbanización popular en la Ciudad de México, México, Instituto de Investigaciones Económicas, Universidad Nacional Autónoma de México, Nuestro Tiempo.

Morelos, José Benigno (1987), "Empleo y sismo: la situación ocupaciona] de la población damnificada", en Estudios Demográficos y Urbanos, vol. 2, núm. 1, ene.-abr., México, El Colegio de México, pp. 9-25.

Moreno Toscano, Alejandra y Sonia Lombardo de Ruiz (1984), Fuentes para la historia de la Ciudad de México 1810-1979, México, INAH.

Navarro, Bernardo (1984), "El metro y la Ciudad de México", en Revista Mexicana de Sociología, vol. 46, núm. 4, oct.-dic., México, pp. 85-104. [1988] El traslado de la fuerza de trabajo en la Ciudad de México, México, Ed. Plaza y Valdés, Departamento del Distrito Federal, Col. Desarrollo urbano. Desafíos de una gran metrópoli.

y Ovidio González (1989), Metro, metrópoli, México, México, UAMXochimilco, UNAM, Instituto de Investigaciones Económicas.

Negrete Salas, Ma. Eugenia y Héctor Salazar Sánchez (1986), "Zonas metropolitanas en México, 1980", en Estudios Demográficos y Urbanos, vol. 1, nủm. 1, ene.-abr., El Colegio de México, pp. 97-124.

Núñez, Óscar (1982a), Causas sociales y políticas en la movilización de los colonos en el D. F. 1970-1973, México, Facultad de Arquitectura Autogobierno.

[1982b], "Infonavit. Un sistema corporativo para asalariados bajos", en E. Pradilla (comp.), Ensayos sobre el problema de la vivienda en América Latina, México, UAM-Xochimilco, pp. 345-418.

[1984], Cambios culturales en los barrios periféricos de la Ciudad de México: notas teórico-analíticas, México, UnAM, Col. Cuader- 
nos de la Facultad de Arquitectura.

[1990], "¿Masas o asociaciones en el origen del movimiento urbano popular?", en Sociológica, año 5 , núm. 12, ene.-abr., UAM-Azcapotzalco, pp. 129-149.

[en prensa], Innovaciones democrático culturales del movimiento urbano popular, México, UNAM.

Oliveira, Orlandina de (1989), "La participación femenina en los mercados de trabajo urbanos en México: 1970-1980", en Estudios Demográficos y Urbanos, vol. 4, núm. 3, sept.-dic., El Colegio de México, pp. 365-494.

, Humberto Muñoz y Claudio Stern (comps.) (1981), Migración y desigualdad social en la Ciudad de México, México, El Colegio de México.

, Brígida García y Humberto Muñoz (1985), "Los trabajadores y sus unidades domésticas en la Ciudad de México", en Reproducción de la Población y Desarrollo, Consejo Latinoamericano de Ciencias Sociales (Clacso), Comisión de Población y Desarrollo y Sistema Estatal de Análisis de Datos (SEADE], núm. 4, pp. 265-280.

Palacios, Juan José (1989a), "¿Descentralización en medio de la crisis?", en Estudios Demográficos y Urbanos, vol. 4, núm. 2, mayo-ago., El Colegio de México, pp 265-280.

(1989b), La política regional en México, 1970-1982, México, Universidad Autónoma de Guadalajara.

Peña, Guillermo de la (1986), "Mercados de trabajo y articulación regional: apuntes sobre el caso de Guadalajara y el occidente mexicano", en Cambio regional, mercado de trabajo y vida obrera en Jalisco, Guadalajara, El Colegio de Jalisco, Col. Estudios Sociales, núm. 1. (1990), "¿Un nuevo tipo de trabajador urbano?", en Crisis, conflicto y sobrevivencia. Estudio sobre la sociedad urbana en México, México, Universidad de Guadalajara-CIESAS, pp. 113-118.

y Agustín Escobar [comps.] [1986], Cambio regional, mercado de trabajo y vida obrera en Jalisco, Guadalajara, El Colegio de Jalisco. et al. (comps.) [1990), Crisis, conflicto y sobrevivencia. Estudio so- bre la sociedad urbana en México, México, Universidad de Guadalajara-CIESAS.

Perló, Manuel (1981), "Algunas consideraciones sobre los problemas financieros de la Ciudad de México", en Lecturas del CEESTEM, vol. 3, México.

[1989a), Historia de las obras, planes y problemas hidráulicos en el Distrito Federal: 1880-1987, IISUNAM, Taller de Investigación, núm. 6.

(1989b), "La Ciudad de México: ¿deben terminarse los subsidios?", en Demos, Carta demográfica sobre México, núm. 2, pp. 31-32.

[1989c), "Problemas sociopolíticos para la utilización de las aguas residuales", en G. Quadri (comp.), Aguas residuales de la Zona Metropolitana de la Ciudad de México. Impactos y perspectivas, México, Fundación Friedrich Ebert/DDF.

Pírez, P. (1984), "Inversión federal y concentración metropolitana en la 
Ciudad de México", en Revista "A" (Revista de Ciencias Sociales y Humanidades), vol. $v$, núm. 11, UAM-Azcapotzalco, pp. 31-56.

Portillo, Álvaro (1984), El arrendamiento de vivienda en la ciudad, México, UAM-Iztapalapa, Col. Cuadernos Universitarios, núm. 16.

Pradilla, Emilio (1982), "Autoconstrucción, explotación de la fuerza de trabajo y políticas del Estado en América Latina", en E. Pradilla (comp.), Ensayos sobre el problema de la vivienda en América Latina, México, UAM-Xochimilco, pp. 267-344.

[1988), "Crisis y arquitectura de subsistencia en México", en $O$. Terrasas y E. Preciat (coords.), Estructura territorial de la Ciudad de México, México, Ed. Plaza y Valdés, DDF, Col. Desarrollo Urbano, Desafíos de una gran metrópoli, pp. 45-78.

(1990), "Las políticas neoliberales y la cuestión territorial", en Sociología, año 5, núm. 12, México, UAM-Azcapotzalco, pp. 47-73.

y C. Castro (1989), "Crisis y reestructuración económica y territorial", en Ciudades, núm. 1, México, RNIU.

Programa Universitario Justo Sierra (1984), El desarrollo urbano de México: problemas y perspectivas, México, UNAM.

Puente, Sergio (1988), "La calidad material de vida en la Zona Metropolitana de la Ciudad de México", en Puente y Legorreta (coords.), Medio ambiente y calidad de vida, México, Plaza y Valdés/DDF, pp. 13-107.

Quintanilla, Ernesto (1986), "Jerarquía de centros según flujos de personas en el área metropolitana de Monterrey", en Estudios Demográficos y Urbanos, vol. 1, núm. 3, sept.-dic., El Colegio de México, pp. 423-442.

(1989), "Trabajadores migrantes en el área metropolitana de Monterrey", en Estudios Demográficos y Urbanos, vol. 4, núm. 3, sept.dic., El Colegio de México, pp. 495-520.

Ramírez, Juan Manuel (1984), "Los movimientos sociales urbanos en México: elementos para una caracterización", en Nueva Antropología, vol. vI, núm. 24, México.

(1986), El movimiento urbano popular en México, México, Siglo XXI Editores.

(coord.) (1987), D. F. gobierno y sociedad, México, Ed. El Caballito. (1989a), Actores sociales y proyecto de ciudad, México, Ed. Plaza y Valdés.

[1989b), "Los objetivos de la Ley General de Asentamientos Humanos", en Una década de planeación urbano-regional en México, 1978-1988, México, El Colegio de México, pp. 27-54.

Regalado Santillán, Jorge (1986), "El movimiento popular independiente en Guada]ajara", en Jaime Tamayo (coord.), Perspectivas de los movimientos sociales en la región centro-occidente, México, Línea-Instituto de Estudios Sociales de la Universidad de Guadalajara-IIS-UNAM.

Rello, Fernando (1988), "Los aparatos de distribución de alimentos en la Ciudad de México", en Puente y Legorreta (coords.), Medio ambiente y la calidad de vida, México, Ed. Plaza y Valdés, Departamento del Distrito Federal, pp. 165-188.

y Demetrio Sodi (1989), Abasto y distribución de alimentos en las 
grandes metrópolis. El caso de la Ciudad de México, México, Ed. Nueva Imagen.

Restrepo, Ivan (1982), La basura: consumo y desperdicio en el Distrito Federal, México, Instituto Nacional del Consumidor.

Reyes Domínguez, Guadalupe y Ana María Rosas Mantecón [1985), "Cultura y organización popular: el caso de Tepito", en Revista Iztapalapa, año 6, núm. 12-13, ene.-dic., UAM, pp. 181-197.

Roberts, Bryan (1986), Industrialización, clase obrera y mercado de trabajo", en Cambio regional, mercado de trabajo y vida obrera en Jalisco, Guadalajara, E] Colegio de Jalisco.

Robinson, Nancy (1980), The politics of low income housing in Mexico; a case study of INFONAVIT, the workers' housing fund, Stanford, Stanford University Press.

Rodríguez Velázquez, Daniel (1986), "La organización popular ante el reto de la reconstrucción", en Revista Mexicana de Ciencias Políticas y Sociales, nueva época, año xxxıI, núm. 123, ene.-mar., México, UNAM, pp. 59-79.

Román Segovia, Guido (1983), “Una modalidad de financiamiento para la producción de viviendas en México: el caso Fov1", tesis de maestría en desarrollo urbano, México, El Colegio de México.

[1989], "El consumo alimentario de la población de bajos ingresos en la Ciudad de México", en Estudios Demográficos y Urbanos, vol. 4, núm. 2, mayo-ago., El Colegio de México, pp. 377-394.

Romero, Laura Patricia [1990), "Cultura política y movimientos sociales en Guadalajara", en Crisis, conflicto y sobrevivencia. Estudio sobre la sociedad urbana en México, México, Universidad de GuadalajaraCIESAS, pp. 457-468.

Rubalcava, Rosa María (1990), "Servicios urbanos y calidad de vida", en Crisis, conflicto y sobrevivencia. Estudio sobre la sociedad urbana en México, México, Universidad de Guadalajara-CIESAS, pp. 317-321.

y Martha Schteingart (1985), "Diferenciación socio-espacial intraurbana en el área metropolitana de la Ciudad de México", en Estudios Sociológicos, vol. 3, núm. 9, sept.-dic., El Colegio de Méxíco, pp. 481-511.

Ruiz, Crescencio [1990], "Distribución de población y crisis económica en los años ochenta: dicotomías y especulaciones", en Revista Mexicana de Sociología, año LII, núm. 1, ene.-mar., UNAM, pp. 185-203.

Safa, Patricia (1987), "Movimientos urbanos y necesidades populares. E] caso de Santo Domingo de los Reyes", en Revista Iztapalapa, año 7, núm. 14, jun.-dic., México, UAM, pp. 147-161.

Sahab Haddad, Elías (1986), "El agua en el Valle de México", en Vivienda, vol. 10, núm. 1, ene.jun., México, pp. 116-123.

Salazar Sánchez, Héctor (1984), "Dinámica y estructura industrial de las áreas urbanas de las ciudades de Puebla, Querétaro yToluca: un análisis de cambio y participación (1960-1970)", tesis de maestría en desarrollo urbano, México, El Colegio de México.

Sánchez Carrillo, C. y A.R. Moreno Sánchez (1987), "La morbimortalidad debida a los sismos de septiembre de 1985 en la Ciudad de México", 
en Salud Pública de México, vol. 29, núm. 5, sep.-oct., México.

Schteingart, Martha (1981), Crecimiento urbano y segregación espacial en la Ciudad de México, México, Centro de Estudios Económicos y Sociales del Tercer Mundo, Col. Lecturas del CEeSTEM, vol. 1, núm. 3. (1982a), "El caso de México", en E. Pradilla (comp:), Ensayos sobre el problema de la vivienda en América Latina, México, UAMXochimilco, pp. 59-80.

[1982b], "Elementos para un balance de la acción habitacional de] Estado en México [1970-1980)", en Habitación, núm. 7-8, jul.-dic.

(1983a), "La incorporación de la tierra rural de propiedad social a la lógica capitalista del desarrollo urbano: el caso de México", en Relación Campo-Ciudad. La tierra, recurso estratégico para el desarrollo y la transformación social, México, SIAP.

(1983b), "La promoción inmobiliaria en el área metropolitana de la Ciudad de México (1960-1980), en Demografía y Economía, vol. xvII, núm. 53, El Colegio de México, pp. 83-105.

(1986), "Movimientos urbanos-ecológicos en la Ciudad de México: el caso del Ajusco (1985-1986)", en Estudios Políticos, nueva época 4 y 5 [4-1), México.

[1988), "La vivienda terminada (Producción Habitaciona] y Promoción Inmobiliaria en la Zona Metropolitana de la Ciudad de Méxicol", en Procesos habitacionales en la Ciudad de México; México, Sedue-1/AM, Col. Cuadernos Universitarios, núm. 51, pp. 105-140. (coord.) (1989a), Las ciudades latinoamericanas en crisis, México, Ed. Trillas.

[1989b), Los productores del espacio habitable. Estado, empresa y sociedad en la Ciudad de México. México, El Colegio de México.

y José Luis Lezama (1986), "Crisis urbana y respuestas populares.

E] impacto del sismo en la Ciudad de México", en Estudios Latinoamericanos, INAM.

Scott, J. (1982), Urban and spatial development in Mexico, International Bank for Reconstruccion and Development World Bank.

Secretaría de Desarrollo Urbano y Ecología (1984), Programa Nacional de Desarrollo Urbano y Vivienda, 1984-1988, México. (1990a), Programa Nacional de Desarrollo Urbano 1990-1994, México. (1990b). Programa Nacional de Vivienda, México.

Selby. Henry, Arthur Murphy, Ear] Morris y Mary Winter (1990), "La familia urbana mexicana frente a la crisis", en Crisis. conflicto y sobrevivencia. Estudio sobre la sociedad urbana en México, México. Universidad de Guadalajara-(:IKSAS, pp. 369-388.

Spíndola, Alejandro y Efrén Ortiz Villaseñor [1985], "El consumo de alimentos en épocas de crisis: resultados de una prueba piloto en la Delegación Cuauhtémoc del Distrito Federa]". en Estudios Sociológicos. vol. III. núm. 8, mayo-ago., E] Colegio de México, pp. 215-262.

Stinson Orti\%. Yvonne (1983). "l.os rendimientos a la escolaridad en el área metropolitana de Monterrey", en Demografia y Economía, vol. xi'll, núm. 4-56, El Colegio de México, pp. 389-515.

Suárez Viila, Luis (1985). "Urban growth and manufacturing change in 
the United States-Mexico borderlands: A conceptual framework and an empirical analysis", in Annals of Regional Science 19[3].

Tamayo, Sergio (1988), "Democracia en la ciudad desde los barrios", en Política y movimientos sociales en la Ciudad de México, México, Ed. Plaza y Valdés, Departamento del Distrito Federal, Col. Desarrollo Urbano. Desafíos de una gran metrópoli, pp. 97-126.

Terrazas Revilla, Óscar (1988), "De la ciudad central a la ciudad interior", en Estructura Territorial de la Ciudad de México, México, Ed. Plaza y Valdés, Departamento del Distrito Federal, Col. Desarrollo Urbano. Desafíos de una gran metrópoli, pp. 79-100.

y E. Preciat (coords.) (1988), Estructura territorial de la Ciudad de México, México, Ed. Plaza y Valdés, Departamento del Distrito Federal, Col. Desarrollo Urbano. Desafíos de una gran metrópoli.

Treviño Cantú, Jesús Antonio (1986), "Emplazamiento industrial y problema urbano (reflexiones a partir de un estudio de caso)", tesis de maestría en desarrollo urbano, México, El Colegio de México.

Tokman, Víctor E. [1983), "The influence of the urban informal sector on economic inequality", New York, St. Martin's Press.

Varley, Ann (1985), "La zona urbana ejidal y la urbanización de la Ciudad de México", en Revista "A" (Revista de Cjencias Sociales y Humanidades], vol. IX, núm. 25, UAM-Azcapotzalco.

Velázquez Gutiérrez, Luis Arturo (1989), Dinámica poblacional: urbanización y migración hacia Guadalajara y dentro del contexto del desarrollo regional, tesis de maestría en demografía, El Colegio de México.

Vellinga, Menno [1988), "La dinámica del desarrollo capitalista periférico. Crecimiento económico y distribución del ingreso en Monterrey", en Monterrey. Siete estudios contemporáneos, Monterrey, Universidad Autónoma de Nuevo León, pp. 21-54.

Verduzco, Basilio (1990), "Centralidad urbana y patrones recientes de localización comercial y de servicios en Tijuana", en Estudios Demográficos y Urbanos, vol. 5, núm. 2-14, mayo-ago., El Colegio de México, pp. 275-308.

Villa A., Manuel (1987), "La politización innecesaria: el régimen político mexicano y sus exigencias de pasividad ciudadana a los damnificados", en Estudios Demográficos y Urbanos, vol. 2, núm. 1, ene.-abr., E] Colegio de México, pp. 27-51.

Ward, Peter (1980), Una comparación entre colonias paracaidistas y ciudades perdidas de la Ciudad de México. Hacia una nueva política, México, UAm, División de Ciencias y Artes para el Diseño, Reporte de Investigación, núm. 5.

(1986), Welfare politics in Mexico. Papering over the cracks, London, Allen \& Unwin.

(1989), Políticas de bienestar social en México, 1970-1989, México, Ed. Nueva Imagen.

Yamada, Mutsuo (1983a), Mexico City development and urban problems after the Revolution 1910-1970, Ibaraki, Japan, University of Tsukuba. [1983b), "Mexico City: Development and Urban problems before the Revolution", en Latin American Studies, núm. 7, pp. 1-47. 
Zepeda, Pedro José (1988), "Alimentación y energía en la Zona Metropolitana de la Ciudad de México", en Puente y Legorreta [coords.), Medio ambiente y calidad de vida, México, Ed. Plaza y Valdés, Departamento del Distrito Federal, pp. 137-164.

Ziccardi, Alicia (1986), "Política de vivienda para un espacio destruido", en Revista Mexicana de Sociología, vol. xLvıll, núm. 2, México, pp. 121-194.

(1987), "La industria de la construcción y el Estado cliente", en México: problemas urbano-regionales, México, Ed. García Valdés, Instituto de .Investigaciones Sociales, UNAM, pp. 339-387.

[1989a), "Empresas de la construcción y grandes obras en la Ciudad de México", en Una década de planeación urbano-regional en México, 1978-1988, México, El Colegio de México, pp. 303-348.

(1989b), "Sismos y reconstrucción", en Emilio Duhau y René Coulomb (coords.), La ciudad y sus actores, México, UAM-IFALC, pp. 55-68.

Zún̄iga, Víctor (1987), "Socialización escolar y marginación urbana. El caso de Monterrey, Nuevo León", en Estudios Sociológicos, vol. v, núm. 15, sept.-dic., El Colegio de México, pp. 575-590.

(1988), "Migrantes rurales en la ciudad. Exodo rural, división urbana del trabajo y familia en Monterrey", en Monterrey. Siete estudios contemporáneos, Monterrey,Universidad Autónoma de Nuevo León, pp. 153-180. 